\title{
Lactobacillus casei expressing methylglyoxal synthase causes browning and heterocyclic amine formation in Parmesan cheese extract
}

\author{
N. N. Gandhi, ${ }^{1}$ G. Barrett-Wilt, ${ }^{2}$ J. L. Steele, ${ }^{1}$ and S. A. Rankin ${ }^{1 *}$ \\ ${ }^{1}$ Department of Food Science, and \\ ${ }^{2}$ Biotechnology Center, University of Wisconsin, Madison 53706
}

\section{ABSTRACT}

Undesired browning of Parmesan cheese can occur during the latter period of ripening and cold storage despite the relative absence of reducing sugars and high temperatures typically associated with Maillard browning. Highly reactive $\alpha$-dicarbonyls such as methylglyoxal (MG) are products and accelerants of Maillard browning chemistry and can result from the microbial metabolism of sugars and AA by lactic acid bacteria. We demonstrate the effects of microbially produced MG in a model Parmesan cheese extract using a strain of Lactobacillus casei $12 \mathrm{~A}$ engineered for inducible overexpression of MG synthase ( $m g s A$ ) from Thermoanaerobacterium thermosaccharolyticum HG-8. Maximum induction of plasmid-born $m g s A$ led to 1.6 $\mathrm{m} M$ MG formation in Parmesan cheese extract and its distinct discoloration. The accumulation of heterocyclic amines including $\beta$-carboline derivatives arising from $m g s A$ expression were determined by mass spectrometry. Potential MG-contributing reaction mechanisms for the formation of heterocyclic amines are proposed. These findings implicate nonstarter lactic acid bacteria may cause browning and influence nutritional aspects of Parmesan by enzymatic conversion of triosephosphates to MG. Moreover, these findings indicate that the microbial production of MG can lead to the formation of late-stage Maillard reaction products such as melanoidin and $\beta$-carbolines, effectively circumventing the thermal requirement of the early- and intermediatestage Maillard reaction. Therefore, the identification and control of offending microbiota may prevent latestage browning of Parmesan. The gene mgsA may serve as a genetic biomarker for cheeses with a propensity to undergo MG-mediated browning.

Key words: methylglyoxal-mediated browning, Parmesan cheese, methylglyoxal synthase, $\beta$-carboline, heterocyclic amine

Received May 10, 2018.

Accepted September 10, 2018.

*Corresponding author: sarankin@wisc.edu

\section{INTRODUCTION}

The development of brown pigmentation can materialize during the latter ripening and storage periods of Parmesan cheese, leading to the economic depreciation of affected cheeses (Divine et al., 2012; Divine and Rankin, 2013). Methylglyoxal (MG) augments and redirects the glycation of peptides, which can subsequently accelerate the formation of brown, nitrogenous, polymeric compounds known as melanoidins. The aldehelic carbonyl carbon of MG is highly electrophilic due to its oxidative state and vicinal position to a second ketonic carbonyl group, readily enhancing elimination, condensation, and other degradation mechanisms. Methylglyoxal-based browning of Parmesan proceeds as a part of the Maillard reaction; however, cold-storage temperatures and the relatively low abundance of reducing sugars do not favor nonenzymatic browning. Instead, evidence suggests that the microbial production of MG is a potential contributor to late-stage browning of Parmesan and is hypothesized to occur due to differences in either the composition or activity of the ripening microbiota caused by 2 different manufacturing styles: direct-salting and brine-salting (McDonald, 1992).

The browning defect is more prominently observed in cheeses that have undergone direct-salting of the curd before pressing, compared with the more time-intensive brine-salting of already pressed cheese. Directly salted cheeses have a uniform dispersion of salt throughout the wheel, whereas a brined cheese has a gradient concentration of salt, with less diffusion toward the center. However, it remains undetermined as to which types of organisms constitute the offending microbiota and to what extent it contributed toward browning.

Selective conditions of ripening cheese result in the decline and autolysis of starter cultures and concurrent rise of adventitious nonstarter lactic acid bacteria (NSLAB) up to $10^{7} \mathrm{cfu} \cdot \mathrm{g}^{-1}$ of cheese (Fitzsimons et al., 2001; Solieri et al., 2012). Nonstarter lactic acid bacteria, predominated by facultative and obligate heterofermentative lactobacilli, significantly influence 
flavor maturation of long-ripened cheeses such as Parmesan. Because NSLAB exist as natural contaminants in the processing environment and within milk, their influence on cheese flavor maturation can be variable. To exert control over NSLAB microbiota of cheese, industry selects adjunct cultures with desired properties and adds these cultures to the cheese at relatively high numbers (Broadbent et al., 2011). Despite the effectiveness of this approach in achieving more consistent flavor maturation, much less is known about discriminating NSLAB that have the propensity to cause or prevent browning.

The enzymatic conversion of the glycolytic intermediate, dihydroxyacetone phosphate (DHAP), into MG and free phosphate is exclusively catalyzed by MG synthase in bacteria (Ferguson et al., 1998; Saadat and Harrison, 1999). During glycolysis, DHAP is converted to glyceraldehyde 3-phosphate $(\mathbf{G A} \mathbf{A P})$ and proceeds toward pyruvate to generate NADH and ATP. The conversion of DHAP to MG provides an alternative pathway of triosphosphate catabolism away from glycolysis, with the conversion of MG to lactic acid being uncoupled from ATP production. Because this glycolytic bypass is energy futile and produces a toxic electrophile as an intermediate, the biological function of MG synthase is much debated.

An increasingly cited explanation is that MG synthase functions as an overflow mechanism to prevent the accumulation of phosphorylated glycolytic intermediates while averting phosphate starvation of glycolysis (Cooper, 1984; Booth et al., 2003; Weber et al., 2005). The conversion of GA3P to glycerate 1,3-bisphosphate by GA3P dehydrogenase requires phosphate and $\mathrm{NAD}^{+}$; therefore, the dephosphorylation of DHAP by MG synthase replenishes depleted phosphate levels. In turn, MG synthase is strongly inhibited by phosphate as well as the glycolytic intermediates 3-phosphoglycerate and phosphoenolpyruvate (Hopper and Cooper, 1972; Falahati et al., 2013). Hence, the ability to produce MG, despite its toxicity and metabolic disadvantage, may serve as another degree of control over the EmbdenMeyerhof-Parnas (EMP) pathway in some bacteria.

Determining whether a cheese environment supports physiological conditions for MG production through persistent MG synthase activity has not been explored. Moreover, reaction products arising from the microbial production of MG in complex matrices such as cheese have yet to be evaluated for their contribution toward functional and nutritional aspects including browning. In this study, we employed a typical species of NSLAB, Lactobacillus casei, to overexpress MG synthase growing in a Parmesan cheese extract (PCE) to determine the extent of browning and elucidate compounds arising from microbially produced MG. We validated that overexpressing MG synthase leads to increased production of MG, discoloration of PCE, and formation of heterocyclic amine compounds. Among these heterocyclic amines, we structurally validated the presence of $\beta$-carboline derivatives using commercially available standards.

\section{MATERIALS AND METHODS}

\section{Bacterial Strains and Growth Conditions}

Stock cultures of L. casei $12 \mathrm{~A}$ and Escherichia coli MC1061 sub-cloning host were maintained at $-80^{\circ} \mathrm{C}$ with $15 \%$ (vol/vol) glycerol in de Man, Rogosa, and Sharpe (MRS) and Luria-Bertani (LB) medium (BD Biosciences, Sparks, MD), respectively. Derivatives of pSIP411 were maintained in $L$. case $i$ and $E$. coli using 2.5 and $500 \mu \mathrm{g} / \mathrm{mL}$ of erythromycin (Erm), respectively. Working cultures of $L$. casei in PCE were prepared from frozen stocks by a single transfer in MRS and one successive $0.1 \%$ (vol/vol) transfer in PCE. All sub-cultures and working cultures of $L$. case $i$ were propagated at $37^{\circ} \mathrm{C}$, without shaking, for 16 to $18 \mathrm{~h}$. Escherichia coli MC1061 was propagated in $\mathrm{LB}$ aerobically at $37^{\circ} \mathrm{C}$ overnight. The pSIP-inducer was obtained as a $98 \%$ pure synthesized peptide (Peptide 2.0, Chantilly, VA) and $100 \mathrm{ng} / \mathrm{mL}$ was added to $L$. casei cultures once optical density at $600 \mathrm{~nm}\left(\mathbf{O D}_{600}\right)=0.3$ was reached, when applicable.

\section{Parmesan Cheese Extract}

The PCE was obtained from a 10-mo-old Parmesan cheese and processed by the Western Dairy Center at Utah State University. A Parmesan cheese block was cut into 5.08-cm cubes and processed through a Commitrol grinder (Urschel, Chesterton, IN) using a 0.317$\mathrm{cm}$ cutting head. The ground cheese was vacuum sealed and cooled at $4^{\circ} \mathrm{C}$ for $24 \mathrm{~h}$. A minimum of $54.4 \mathrm{~kg}$ of cheese was combined with $265 \mathrm{~L}$ of deionized water in a stainless-steel, steam-heated, jacketed vat with a total capacity of $321 \mathrm{~L}$. The cheese and water mixture was continuously stirred and heated from $15.5^{\circ} \mathrm{C}$ to $48.8^{\circ} \mathrm{C}$ over $40 \mathrm{~min}$ and held at $48.8^{\circ} \mathrm{C}$ for $20 \mathrm{~min}$. Cheese solids were removed from the cheese-water extract by processing through a cheesecloth. The extract $(\sim 265 \mathrm{~L})$ was processed through 2 spiral-wound UF membranes with a molecular weight cutoff of $5,000 \mathrm{kDa}$ while using an operating flow of $18.9 \mathrm{~L} / \mathrm{min}$, operating temperature of $48.8^{\circ} \mathrm{C}$, and operating pressure of 100 to $1,000 \mathrm{kPa}$. The permeate was collected and recycled once with the concentrated retentate through the UF system before a final reverse osmosis filtration treatment. The reverse osmosis filtration system used the aforementioned con- 
ditions albeit at an operating pressure of 3,000 to 6,000 $\mathrm{kPa}$. The extract was packaged and stored at $-20^{\circ} \mathrm{C}$. Before use as a bacterial growth medium, $2 \%$ glucose was added to PCE, filter sterilized $(0.2 \mu \mathrm{m}$ filter, Bottle-top Nalgene, Thermo Fisher Scientific, Waltham, $\mathrm{MA})$, and stored at $4^{\circ} \mathrm{C}$.

\section{Construction of MG Producing L. casei 12A}

All primers used for the construction of $L$. casei harboring pSIP411_mgsA are listed in Table 1. The MG synthase (mgsA) from Thermoanaerobacterium thermosaccharolyticum HG-8 (GenBank AF127246.1) was codon optimized for expression in L. casei using JCAT (Grote et al., 2005) and synthesized by The US Department of Energy Joint Genome Institute (Walnut Creek, CA; Supplemental Figure S1; https://doi.org/ 10.3168/jds.2018-15042). The plasmid pSIP411_gusA ( $\beta$-glucuronidase) was obtained from Lars Axelsson (Norwegian Food Research Institute, Ås, Norway) and was used as a control as well as template DNA for the pSIP411 backbone (Sørvig et al., 2005). The plasmid pSIP411_mgsA was constructed using Gibson Assembly (Gibson et al., 2009). The pSIP411 backbone (5,864 bp) and $m g s A$ gene (405 bp) were amplified using Phusion High-Fidelity DNA Polymerase (New England Biolabs, Ipswich, MA) as per the manufacturer's recommendation. Primers, $60 \mathrm{bp}$ in length, containing 30-bp overlapping regions homologous to the pSIP411 backbone, were used to amplify mgsA. Amplicons were gel purified using using QIAquick Gel Extraction Kit (Qiagen, Hilden, Germany). Gibson Assembly Mastermix was used for a 2-fragment assembly as per the manufacturer's recommendations (New England Biolabs). Gibson reactions were transformed into electrocompetent E. coli MC1061 and transformants were selected on LB plates containing $500 \mu \mathrm{g} / \mathrm{mL}$ of Erm. Positive transformants were screened by colony PCR and the sequence of pSIP411_mgs $A$ was confirmed by Sanger sequencing (University of Wisconsin, Biotechnology Center).

Recombinant plasmid pSIP411_mgsA was transformed into electrocompetent $L$. casei $12 \mathrm{~A}$ as described by Welker et al. (2015). Briefly, cells were grown in MRS containing $2 \%$ glycine to an $\mathrm{OD}_{600}=0.6$, washed with ice-cold sterile deionized and distilled $\mathrm{H}_{2} \mathrm{O}$, and cell slurries re-suspended in $30 \%$ polyethylene glycol (PEG-8000). Cells were treated for $20 \mathrm{~min}$ at room temperature with 1 volume filter sterilized lithium acetate mixture (1.2 M sucrose, $200 \mathrm{~m} M$ lithium acetate, and $20 \mathrm{~m} M$ Tris) and 0.2 volume filter sterilized dithiothreitol before being washed once and re-suspended in PEG-8000. Electroporation was performed in 2-mm cuvettes using a Bio-Rad Gene Pulser (Hercules, CA) set to $2,500 \mathrm{~V}, 25 \mu \mathrm{F}$, and $400 \Omega$. Cells were recovered in MRS containing $0.5 \mathrm{M}$ sucrose for $4 \mathrm{~h}$ before being plated onto MRS containing $2.5 \mu \mathrm{g} / \mathrm{mL}$ of Erm. Positive transformants were confirmed by colony PCR.

\section{Quantification of MG Production and Browning in PCE}

Analyte concentrations of MG and 2,3 hexanedione (internal standard) were determined by derivatization with 1,2-diaminobenzene to form 2-methylquinoxaline and 2,3-diethylquinoxaline, respectively, and measured by GC-MS using methods adapted from Chaplen et al. (1996) and the Compendium of International Analysis of Methods (2010). Early stationary-phase cells of $L$. casei 12A harboring pSIP411_mgsA were inoculated $(0.1 \% \mathrm{vol} / \mathrm{vol})$ into $50 \mathrm{~mL}$ of PCE supplemented with $2 \%$ glucose and $2.5 \mu \mathrm{g} / \mathrm{mL}$ of Erm. Cultures were induced with $100 \mathrm{ng} / \mathrm{mL}$ of pSIP-inducer at $\mathrm{OD}_{600}=0.3$ before being incubated at $37^{\circ} \mathrm{C}$ for $24 \mathrm{~h}$. Uninduced control cultures as well as L. casei $12 \mathrm{~A}$ harboring pSIP411_gusA ( $\beta$-glucuronidase) were included alongside as controls.

The PCE supernatants were visually inspected for browning before quantification of MG using GC-MS. A browning unit (BU) was used to define visualized discoloration of PCE (defined as the spectrophotometric difference measured at 420 and $500 \mathrm{~nm}$ ). An increase in BU represents browning of PCE. Added to each 50$\mathrm{mL}$ sample was $17.5 \mathrm{~m} M 2$,3-hexanedione. Each sample was treated with $1.94 \mathrm{~mL}$ of $70 \%$ perchloric acid and incubated on ice for 30 min before being centrifuged

Table 1. Primers used for the construction of pSIP411 expressing methylglyoxal synthase (mgsA)

\begin{tabular}{lll}
\hline Primer & Description & Sequence $^{1}$ \\
\hline mgsA_F & Gibson assembly & aatactattacaaggagattttagccatgGTTAACTTGAACATCGCTTTGATCGCTCAC \\
mgsA_R & & accegggtaccgaattcctcgagtctagaTTACTTAACAGCGTTACGCCATTCCAACAA \\
pSIP411_F & & TCTAGACTCGAGGAATTCGGTACCCCGGGT \\
pSIP411_R & GGCTAAAATCTCCTTGTAATAGTATTTTATAGATACATATATGCTGGCC \\
MCS_F & Screening & GCTCCAGATCTACCGGTTTAAT \\
MCS_R & & CTATCGAAAGCGAAATCAAACGAA \\
\hline
\end{tabular}

${ }^{1}$ Gibson primers: uppercase and lowercase nucleotides represent the annealing and overhanging regions, respectively. 
at $11,400 \times g$ for $10 \mathrm{~min}$ at $4^{\circ} \mathrm{C}$. Supernatants were separated from cell pellets and allowed to reach room temperature before being brought to a $\mathrm{pH}$ of 8.0 using $\mathrm{NaOH}$. Added to each sample was $20 \mathrm{mg}$ of 1,2-diaminobenzene. Derivatization occurred at $60^{\circ} \mathrm{C}$ for 3 $\mathrm{h}$ before samples were brought to room temperature and a $\mathrm{pH}$ of 2.0 using $\mathrm{H}_{2} \mathrm{SO}_{4}$. Liquid-liquid extraction was performed twice using $5 \mathrm{~mL}$ of dichloromethane and decanting the lower phase using a separatory funnel. Extracts were dried over $1 \mathrm{~g}$ of anhydrous $\mathrm{Na}_{2} \mathrm{SO}_{4}$, decanted, and syringe filtered into 2-mL GC-MS vials. Commercial solutions of 2,3-hexanedione, 2-methylquinoxaline, 2,3-diethylquinoxaline, and tablets of 1,2-diaminobenzene were purchased from Sigma-Aldrich (St. Louis, MO).

The gas chromatograph (Agilent 6890N, Agilent Technologies Inc., Palo Alto, CA) was fitted with a fused-silica capillary column (RTx-5MS, $30 \mathrm{~m}$ long $\times$ $0.25 \mathrm{~mm}$ i.d. $\times 0.5 \mu \mathrm{m}$ film thickness; Restek Corp., Bellefonte, PA) and paired with a mass selective detector (Agilent 5973 MS, Agilent Technologies Inc.). The initial temperature of the front inlet was $250^{\circ} \mathrm{C}$ at a flow of $40.0 \mathrm{~mL} / \mathrm{min}$, using helium as the carrier gas. The volume injected was $1 \mu \mathrm{L}$, splitless. The oven temperature was held at $60^{\circ} \mathrm{C}$ for $1 \mathrm{~min}$, then programmed to increase at a rate of $10^{\circ} \mathrm{C} / \mathrm{min}$ to $220^{\circ} \mathrm{C}$ with a final isothermal period of $10 \mathrm{~min}$. Chemstation Software (Rev. D.02.00 SP1, Agilent Technologies Inc.) was used to identify 2-methylquinoxaline and 2,3-diethylquinoxaline representing MG and 2,3-hexanedione, respectively. Analytes were confirmed by comparison of retention times to purchased standards and the selected ion monitoring method; MG: ions $\mathrm{m} / z=117$ and 144, 2,3-hexanedione: ions $m / z=158$ and 171 . The quantitative determination of $\mathrm{MG}$ and 2,3-hexanedione was performed using a multiple-point external standard curve of 2-methylquinoxaline and 2,3-diethylquinoxaline from $10 \mu M$ to $2 \mathrm{~m} M$ and analyte concentrations were normalized to the maximum $\mathrm{OD}_{600}$ achieved after growth. Statistical significance of biological triplicates from the control was determined using a paired $t$-test with $\alpha$ of $<0.05$.

\section{Heterocyclic Amine Detection}

Lactobacillus casei 12A harboring pSIP411_mgsA was inoculated $(0.1 \%)$ into $5 \mathrm{~mL}$ of PCE containing $2 \%$ glucose and $2.5 \mu \mathrm{g} / \mathrm{mL}$ of Erm. Experimental cultures were induced with $100 \mathrm{ng} / \mathrm{mL}$ of pSIP-inducer at $\mathrm{OD}_{600}$ $=0.3$ before being incubated at $37^{\circ} \mathrm{C}$ for $72 \mathrm{~h}$. Cultures were centrifuged at $11,400 \times g$ for 5 min at $4^{\circ} \mathrm{C}$ and supernatants were passed through a $0.2 \mu \mathrm{M}$ filter before being frozen at $-20^{\circ} \mathrm{C}$ until further analysis. Analysis was performed in biological triplicate.
Amicon ultra $10 \mathrm{kDa}$ molecular weight cutoff filters (Millipore, Temecula, CA) were first rinsed with 18 MOhm of deionized water and then $200 \mu \mathrm{L}$ of sample was applied. Samples were centrifuged at $14,000 \times g$ for $20 \mathrm{~min}$ at room temperature and $\sim 150 \mu \mathrm{L}$ of filtrate were removed. Samples were analyzed by liquid chromatography (LC)-MS using an Agilent 1969A ESI-TOF in positive ion mode coupled with a 1200 series Binary Pump SL. Sample injection volume was $5 \mu \mathrm{L}$. Solvents were $0.1 \%$ formic acid in water $(\mathrm{A})$ and $0.1 \%$ formic acid in acetonitrile (B). The column was a Phenomenex Synergi Hydro-RP (Torrance, CA), 150 $\mathrm{mm} \times 2 \mathrm{~mm}$ held at $25^{\circ} \mathrm{C}$. Sample constituents were gradient eluted over 38 min starting at $0 \% \mathrm{~B}$ held for 2 min, then increasing to $30 \% \mathrm{~B}$ over $30 \mathrm{~min}$, increasing to $95 \%$ B over 6 min, holding for 1 min at $95 \% \mathrm{~B}$, then returning to $0 \% \mathrm{~B}$ over $1 \mathrm{~min}$ and re-equilibrating for 5 min. The flow rate was constant at $250 \mu \mathrm{L} / \mathrm{min}$. Mass spectrometer parameters were $350^{\circ} \mathrm{C}$ gas temperature, $10 \mathrm{~L} / \mathrm{min}$ of drying gas, 35 psig nebulizing gas, 3,600 $\mathrm{V}$ of electrospray ionization (ESI) voltage, fragmentor at $130 \mathrm{~V}$, skimmer at $60 \mathrm{~V}$, and octopole RF (radio frequency) at $250 \mathrm{~V}$. Scans were acquired over the $\mathrm{m} / z$ range 50 to 1,700 at $1.24 \mathrm{scans} / \mathrm{s}$ averaging 10,040 transients/scan. A dual-spray source was used with the main sprayer receiving the HPLC column effluent and the second sprayer receiving internal calibrant solution at $30 \mu \mathrm{L} / \mathrm{min}$. Applied Biosystems MDS Sciex Analyst QS version 1.1 and Agilent MassHunter Workstation version 5.1.2600 was used for data acquisition and analysis (Agilent Technologies Inc., Santa Clara, CA).

\section{Structural Identification of Heterocyclic Amines}

The LC-MS/MS was performed on 8 species previously identified in PCE due to expression of $m g s A$ in L. casei $12 \mathrm{~A}$. Culture conditions and sample preparations were as previously stated. The HPLC used an Agilent 1100 binary pump with column compartment and WPALS thermostatted autosampler. Mass spectrometry was performed on a Sciex QTRAP 5500 in positive ion ESI mode using the TurboIon source. The LC separation was achieved with a Synergi Hydro-RP column (Phenomenex), $150 \mathrm{~mm} \times 2 \mathrm{~mm}$, using solvents containing $0.1 \%$ formic acid in water (A) and $0.1 \%$ formic acid in acetonitrile (B), both purchased as pre-mixed solvents (Thermo Fisher Scientific, LC/ MS grade). Compounds were gradient eluted at 250 $\mu \mathrm{L} / \mathrm{min}$ with the following program: $0 \% \mathrm{~B}$ for $2 \mathrm{~min}$, increase to $30 \%$ B over $30 \mathrm{~min}$, increase to $95 \%$ B over $6 \mathrm{~min}$, hold for $1 \mathrm{~min}$, return to $0 \% \mathrm{~B}$ over $1 \mathrm{~min}$ and re-equilibrate for $15 \mathrm{~min}$. The column was held at $25^{\circ} \mathrm{C}$ and the autosampler was chilled to $6^{\circ} \mathrm{C}$. Injection volume was $5 \mu \mathrm{L}$. The MS/MS was performed in 4 periods 
targeting 2 compounds per period and collecting MS/ MS data at 3 collision energies (10, 20, and 40) per compound. Data were acquired in enhanced product ion mode using the ion trap function of the instrument at a scan rate of $1,000 \mathrm{Da} / \mathrm{s}$ with unit resolution in Q1 for precursor selection and dynamic fill time with a target value of $1 \times 10^{8} \mathrm{cps}$. Source parameters were as follows: CUR 40, CAD high, IS 3250, TEM 650, GS1 45, GS2 40, DP 50, EP 10, and CES 0 (CUR = curtain gas in psi; CAD = collision gas setting; TEM = ionspray temperature; GS1 = nebulizing gas in psi; GS2 = ionspray gas in psi; DP = declustering potential in $\mathrm{V} ; \mathrm{EP}=$ entrance potential in $\mathrm{V}$; $\mathrm{CES}=$ collision energy spread in V). Period 1 (0-16.5 min) precursors were 127 and 143, period 2 (16.5-22 $\mathrm{min})$ precursors were 229 and 217 , period 3 (22-28 $\mathrm{min}$ ) precursors were 331,183 , and period 4 (28-50 min) precursors were 255 and 211. The LC was controlled using Agilent OpenLab CDS/Chemstation C.01.03 and the MS was controlled using Analyst 1.6.2. The MS acquisition was triggered by contact closure from the LC.

\section{Comparison of Unknowns with Standard Compounds by LC-MS/MS}

Based on retention time comparisons between standards and unknown compounds detected in PCE, targeted LC-MS/MS was performed to determine similarity between unknowns and standard compounds. Harman (Sigma-Aldrich), 1,2,3,4-tetrahydro- $\beta$-carboline3-carboxylic acid (Sigma-Aldrich), and 1,2,3,4-tetrahydroharmane-3-carboxylic acid (Sigma-Aldrich) were initially dissolved in dimethyl sulfoxide, then diluted to suitable concentration in $0.1 \%$ formic acid, $50 \%$ acetonitrile in water as a mixed standard containing all 3 compounds. The LC-MS/MS was performed on a Thermo TSQ Quantum Discovery Max triple quadrupole mass spectrometer coupled to Agilent 1100 binary HPLC with WPALS autosampler and column compartment. The HPLC column and gradient were exactly as described above. Targeted full-scan MS/MS was performed on the standards and unknowns in their protonated forms at $m / z 217.1$ (1,2,3,4-tetrahydro- $\beta$ carboline-3-carboxylic acid), 183.1 (Harman), 231.1 (1,2,3,4-tetrahydroharmane-3-carboxylic acid), and $m / z 229.1$, for which no standard was available. The ESI-MS was performed using the HESI-II source at $4,000 \mathrm{~V}$ in positive ion mode with heated electrospray at $400^{\circ} \mathrm{C}$. Sheath gas was set to 30 (arbitrary units), sweep gas was at 0 , auxiliary gas at 1 , and heated capillary at $325^{\circ} \mathrm{C}$. The $\mathrm{MS} / \mathrm{MS}$ parameters for all targeted scans were $0.5 \mathrm{~s}$ scan time, Q1 and Q3 set to $0.7 \mathrm{amu}$ FWHM (full width half max), $40 \mathrm{~V}$ of collision energy, and $1.5 \mathrm{mT}$ of argon as collision gas. Scan ranges were
50 to 240 for $m / z 217.1,50$ to 210 for $m / z 183.1,50$ to 260 for $m / z 231.1$, and 50 to 260 for $m / z 229$. 1 . Spectra were obtained by averaging across the chromatographic peak for each precursor and then applying 7-point boxcar smoothing.

\section{RESULTS}

Using the sakacin-based inducible plasmid pSIP411 to express MG synthase (mgsA) from T. thermosaccharolyticum $\mathrm{HG}-8$ in $L$. casei $12 \mathrm{~A}$ led to the production of 1.6 $\mathrm{m} M \mathrm{MG}$ in PCE (Figure 1). This was found to be a statistically significant increase in MG production compared with the uninduced $m g s A$ control $(0.09 \mathrm{mM})$ and both uninduced and induced gusA ( $\beta$-glucuronidase) controls $(0.009 \mathrm{~m} M)$ as determined using a paired $t$ test with $\alpha$ of $<0.05$. In addition, we established that inducing expressing of $m g s A$ causes visible browning of the PCE supernatant, as represented by the increase from 0.11 to $0.43 \mathrm{BU}$.

We detected 8 compounds in PCE resulting from the expression of $m g s A$ in $L$. casei $12 \mathrm{~A}$ using LC-MS (ESItime of flight; Figure 2). Based on our analysis, the 8 compounds arising from $m g s A$ expression had masses ranging from 126.0313 to $330.1211 \mathrm{~g} / \mathrm{mol}$, which were

\section{Induction of $L$. casei $12 \mathrm{~A}$ mgs $A$}

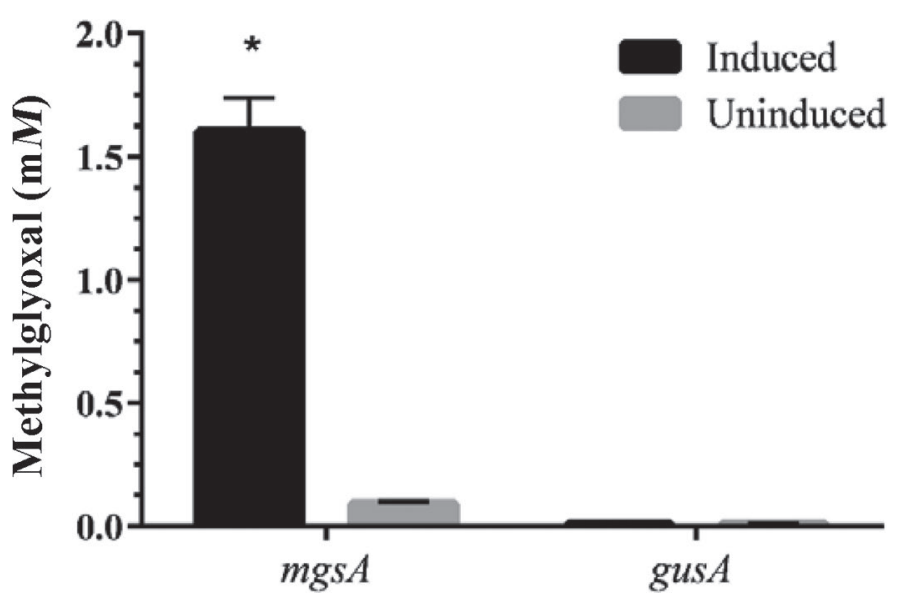

Figure 1. Quantification of methylglyoxal production by Lactobacillus casei $12 \mathrm{~A}$ expressing plasmid-born methylglyoxal synthase $(m g s A)$ growing in Parmesan cheese extract (PCE). Early stationary-phase cells of $L$. casei $12 \mathrm{~A}$ harboring pSIP411_mgsA were inoculated $(0.1 \% \mathrm{vol} / \mathrm{vol})$ into $50 \mathrm{~mL}$ of PCE supplemented with $2 \%$ glucose and $2.5 \mu \mathrm{g} / \mathrm{mL}$ of erythromycin. Cultures were induced with $100 \mathrm{ng} / \mathrm{mL}$ of pSIP-inducer for optical density at $600 \mathrm{~nm}=0.3$ before being incubated at $37^{\circ} \mathrm{C}$ for $24 \mathrm{~h}$. Uninduced control cultures as well as L . casei 12A harboring pSIP411_gusA ( $\beta$-glucuronidase) were included alongside. Methylglyoxal concentrations were determined in PCE supernatant by derivatization with o-phenyldiamine and GC-MS. Statistical significance from the control $\left(^{*}\right)$ was determined using a paired $t$-test with $\alpha$ of $<0.05$. Error bars represent SD of the mean of biological triplicates. 

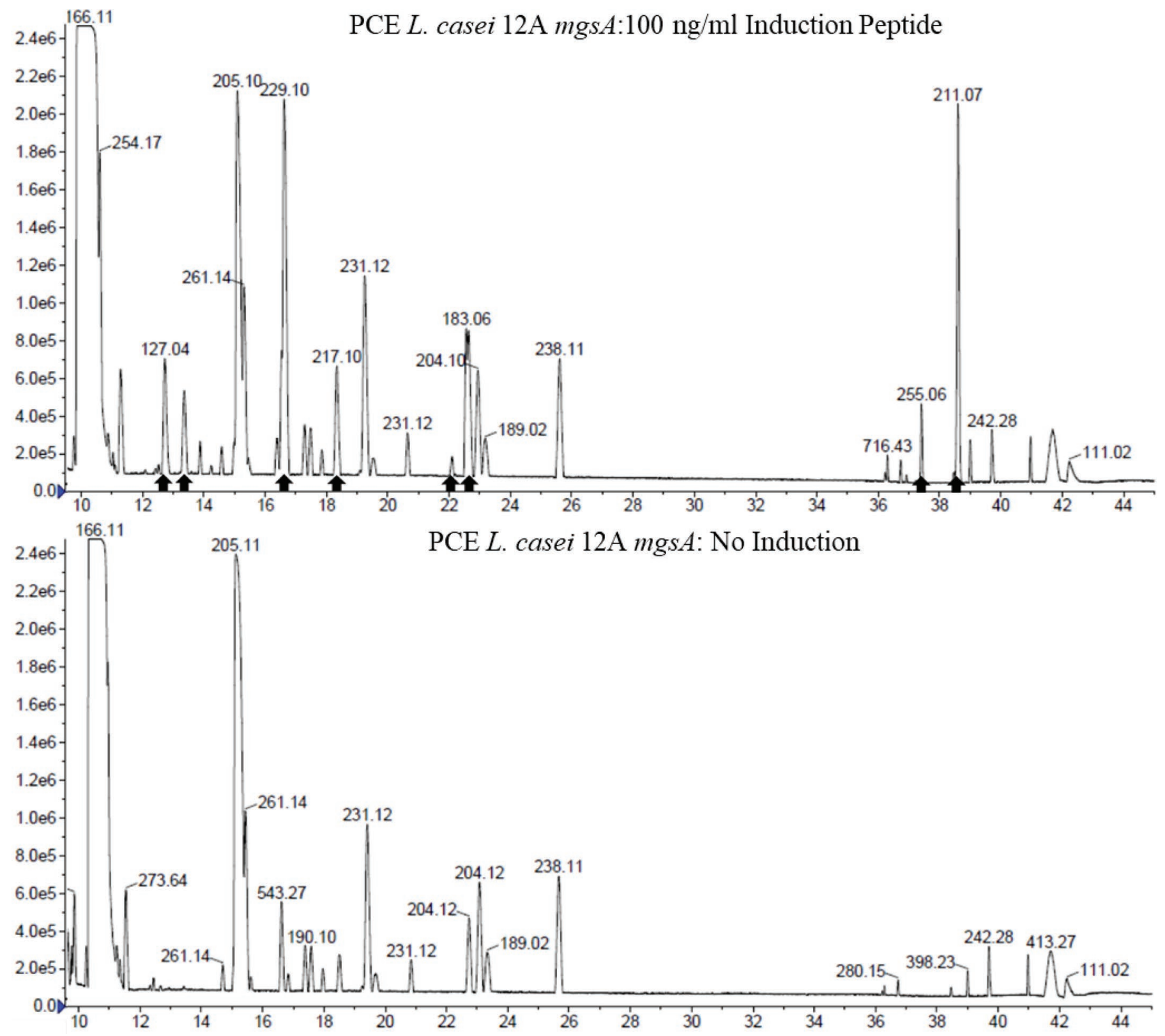

Figure 2. Liquid chromatography-electrospray ionization time-of-flight base-peak chromatograms depicting compounds in Parmesan cheese extract (PCE) resulting from growth of Lactobacillus casei 12A expressing methylglyoxal synthase (mgs A; top). The uninduced control culture is included (bottom). Lactobacillus casei $12 \mathrm{~A}$ harboring pSIP411_mgsA was inoculated into $5 \mathrm{~mL}$ of PCE containing $2 \%$ glucose and $2.5 \mu \mathrm{g} /$ $\mathrm{mL}$ of erythromycin. Cultures were induced with $100 \mathrm{ng} / \mathrm{mL}$ of pSIP-inducer at optical density at $600 \mathrm{~nm}=0.3$ before being incubated at $37^{\circ} \mathrm{C}$ for $72 \mathrm{~h}$. The PCE supernatants were filter sterilized $(0.2 \mu \mathrm{m}$ filter $)$ and frozen at $-20^{\circ} \mathrm{C}$ until further analysis. Samples were filtered $(10 \mathrm{kDa}$ molecular weight cutoff) and analyzed in biological triplicate. Numbers seen above peaks represent the observed ion mass $[\mathrm{M}+\mathrm{H}]$. Peaks $(8)$ unique to methylglyoxal synthase expression are specified by black arrows.

used to predict their chemical composition using the METLIN simple search function. In an attempt to identify these compounds structurally, we used LCMS/MS and different collision energies (10, 20, and 40 $\mathrm{eV})$ to generate mass spectra. Fragment ions and their intensities generated from a collision energy of $40 \mathrm{eV}$ were compared against the METLIN database using
MS/MS spectrum and fragment ion similarity search functions (Table 2).

We detected the formation of $\beta$-carboline derivatives of heterocyclic amines among the compounds formed in PCE due to overexpression of mgsA by L. casei $12 \mathrm{~A}$. Compound $4 \quad\left(\mathrm{C}_{12} \mathrm{H}_{12} \mathrm{~N}_{2} \mathrm{O}_{2}\right)$ was positively identified to be 1,2,3,4-tretrahydro- $\beta$-carboline-3-carboxylic acid 
(TH及CA) based on co-elution and spectral match using a commercially available standard (Figure 3A). The TH $\beta C A$ was the only compound observed to form in $\mathrm{PCE}$ from the exogenous addition of MG (data not shown). Compound $6 \quad\left(\mathrm{C}_{12} \mathrm{H}_{10} \mathrm{~N}_{2}\right)$ closely resembled Harman (1-methyl- $\beta$-carboline) based on similar mass spectra and nearly identical co-elution; however, it is likely the unknown species represents a close isomer (Figure 3B).

The commercial standard for 1,2,3,4-tetrahydroharmane-3-carboxylic acid displayed 2 separate chromatographic peaks at $m / z 231$ and the unknown in the sample at $m / z 231$ also showed 2 separate chromatographic peaks. The first of these peaks co-eluted with the first peak from the standard and showed excellent MS/MS spectral similarity (Figure 4A). Whereas the second peak at $m / z 231$ in the standard and in the sample showed excellent co-elution, the MS/MS spectra displayed some differences, indicating that the structures were not identical (Figure 4B). Additionally, although no standard was identified as a candidate structure for the unknown at $m / z 229$, it is possible that this compound is formed by inclusion of a double bond in the pyridine ring of compound 3 (removal of 2 hydrogen atoms), representing a similar species such as 1-methyl3,4-dihydro- $2 \mathrm{H}$ - $\beta$-carboline-3-carboxylic acid.

Spectral matches for $\mathrm{C}_{13} \mathrm{H}_{8} \mathrm{~N}_{4} \mathrm{O}_{4}, \quad \mathrm{C}_{17} \mathrm{H}_{18} \mathrm{~N}_{2} \mathrm{O}_{5}$, $\mathrm{C}_{9} \mathrm{H}_{10} \mathrm{~N}_{4} \mathrm{O}_{3} \mathrm{~S}$, and $\mathrm{C}_{8} \mathrm{H}_{10} \mathrm{~N}_{4} \mathrm{OS}$ were not found; however, their chemical composition implicate the formation of nitrogenous heterocycles, many of which are inferred to contain pyrazine or imidazole sub-groups. The exception to heterocyclic amine formation is the compound $\mathrm{C}_{6} \mathrm{H}_{6} \mathrm{O}_{3}$, which was found to likely be either a pyrone or quinone derivative.

We outline potential MG-contributing reaction mechanisms that may contribute to the formation of heterocyclic amines (Figure 5). These reactions de- scribe the formation of Strecker aldehydes, pyrazines, imidazo-quinoxalines, and $\beta$-carbolines. The Strecker degradation of glycine or alanine with MG, for example, can lead to the formation of formaldehyde and acetaldehyde, respectively (Nursten, 2005). Second, the formation of alkyl pyrazines is generally linked to Strecker degradation in which the $\alpha$-dicarbonyl undergoes transamination, leading to an $\alpha$-aminocarbonyl compound. The subsequent condensation of $2 \alpha$-aminocarbonyls leads to various substituted pyrazines which offer a low threshold nutty, toasted, or roasted aroma (Rizzi, 2008). For example, the condensation of aminoacetone, the $\alpha$-aminocarbonyl derived from MG, can form 2,5-dimethyl-pyrazine. Furthermore, creatine that is naturally occurring or biosynthesized from glycine and arginine, can self-condense into creatinine and react with pyrazine and aldehyde constituents to form imidazo-quinoxalines (Jägerstad and Skog, 1991; Skog et al., 1992). Last, $\beta$-carboline compounds can be derived from indolethylamines and Strecker aldehydes in a mechanism that likely resulted in the products formed herein. The reaction mechanism begins by the primary amine of an indolethylamine (e.g., tryptamine or tryptophan) molecule performing nucleophilic attack on the carbonyl carbon of an aldehyde to form an imine intermediate. The reaction proceeds by the PictetSpengler reaction, in which the intermediate undergoes ring closure after condensation (Cox and Cook, 1995).

\section{DISCUSSION}

The growth of NSLAB is a critical component for the maturation of many long-ripened cheeses, yet the microbial production of MG can contribute to melanoidin formation, leading to undesired browning of Parmesan cheese and overall economic loss. Ongoing MG synthase activity is one potential source of MG in Parmesan

Table 2. Compounds detected in Parmesan cheese extract after $72 \mathrm{~h}$ of growth of Lactobacillus casei 12A expressing methylglyoxal synthase $(m g s A)^{1}$

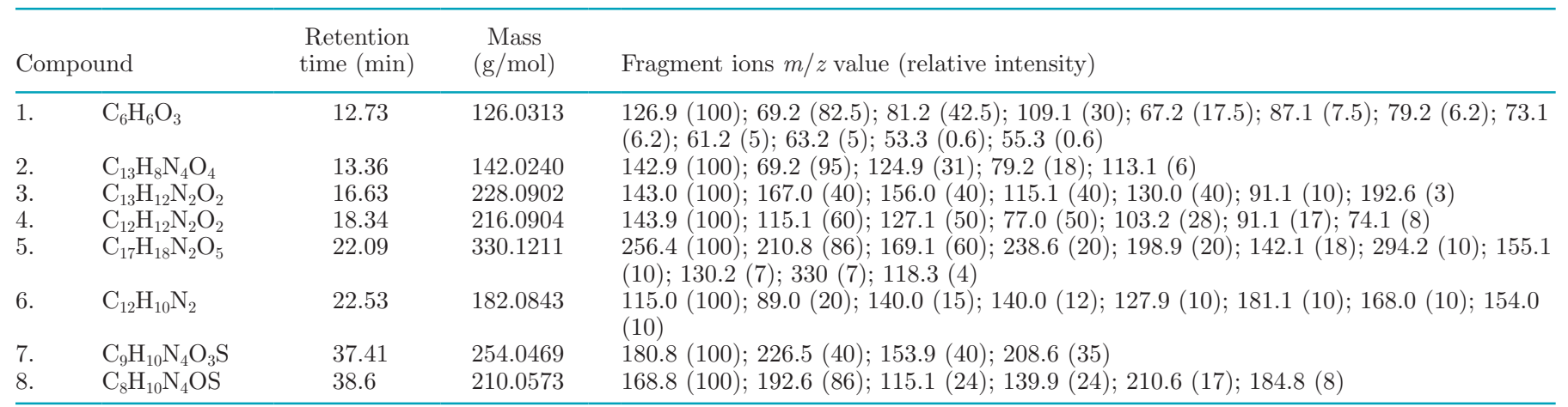

${ }^{1}$ Accurate mass was determined by liquid chromatography (LC) electrospray ionization time-of-flight (Agilent 1969A, Agilent Technologies, Santa Clara, CA). The mass to charge ratio $(\mathrm{m} / z)$ of fragment ions and their relative intensity were generated using a collision energy of 40 eV and determined by LC-MS/MS (Sciex QTRAP 5500, Sciex, Framingham, MA). 


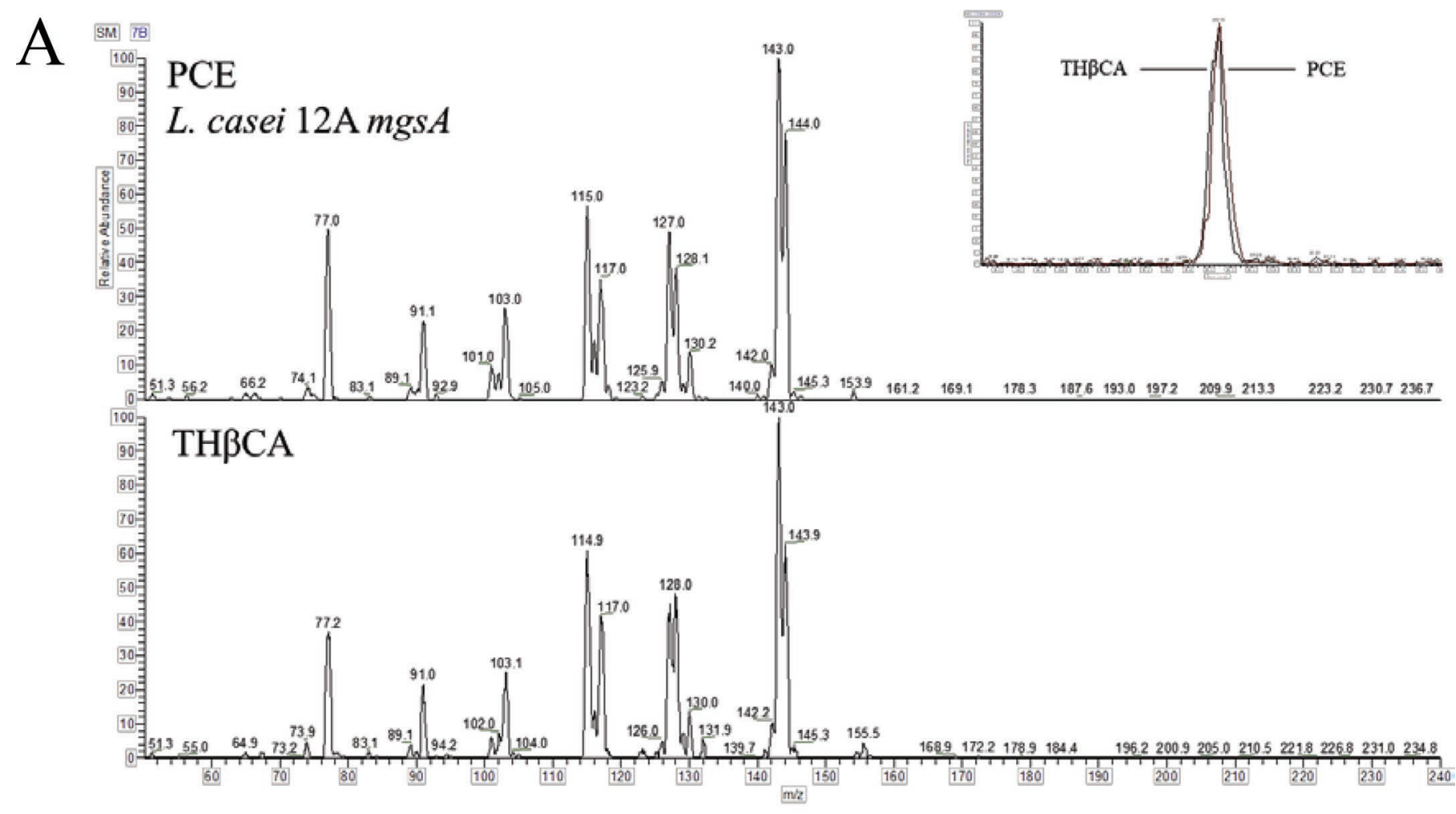

$\mathrm{B}$

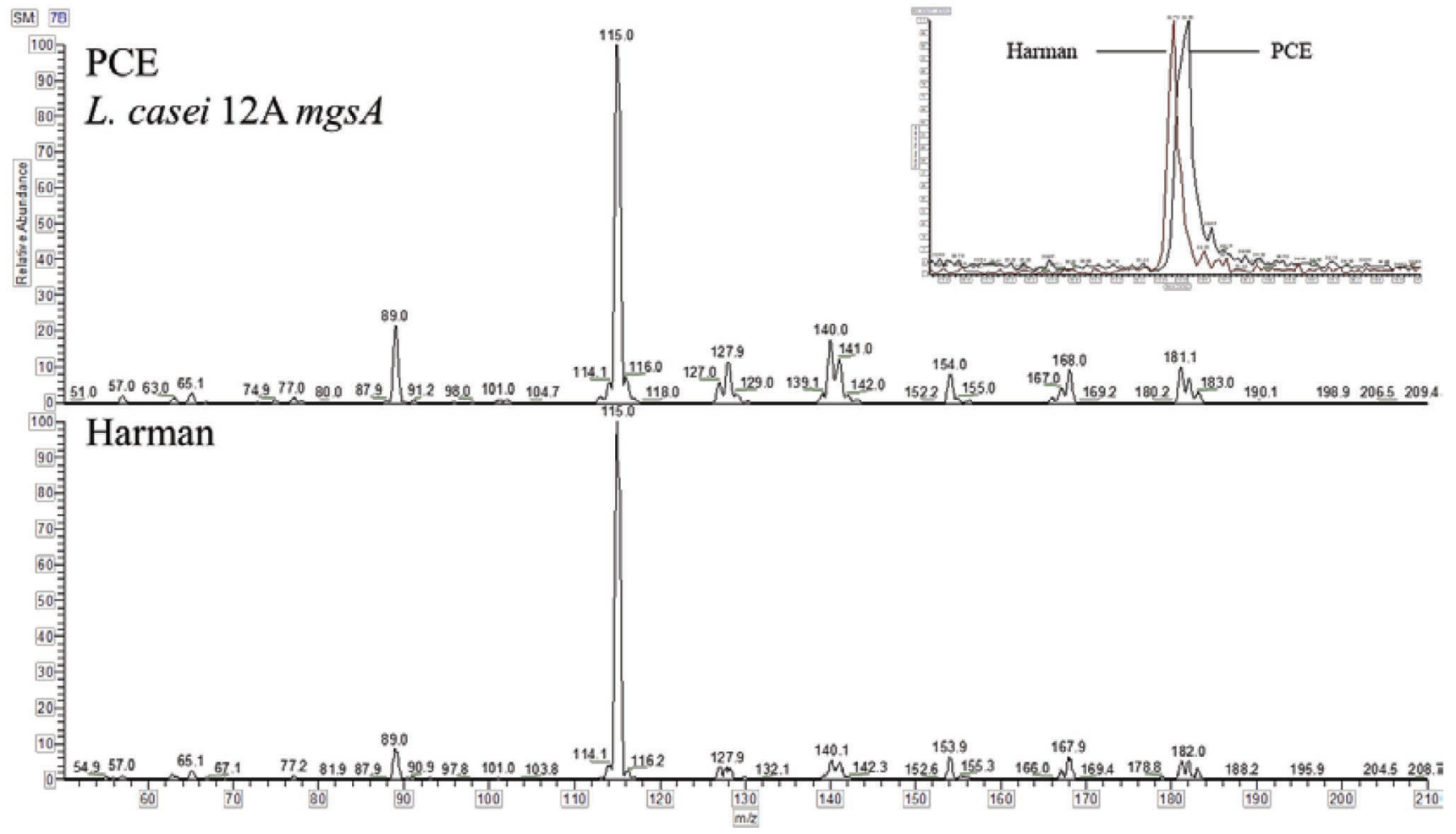

Figure 3. Liquid chromatography tandem mass spectrometry (LC-MS/MS) comparison between $\beta$-carboline derivatives formed in Parmesan cheese extract (PCE) from Lactobacillus casei 12A expressing methylglyoxal synthase ( $m g s A$ ) and 1,2,3,4-tetrahydro- $\beta$-carboline-3-carboxylic acid (TH $\beta \mathrm{CA}$ ) and Harman. (A) Compound 4 and TH $\beta \mathrm{CA}$, and (B) compound 6 and Harman. The mass to charge ratio $(m / z)$ of fragment ions and their relative abundance in samples and commercially available standards were generated using a collision energy of $40 \mathrm{eV}$ and detected by LC-MS/MS (Thermo TSQ Quantum Discovery Max, Thermo Fisher Scientific, Waltham, MA). The co-elution profile of the compound and standard is depicted in the upper right-hand corner of each mass spectrum. 


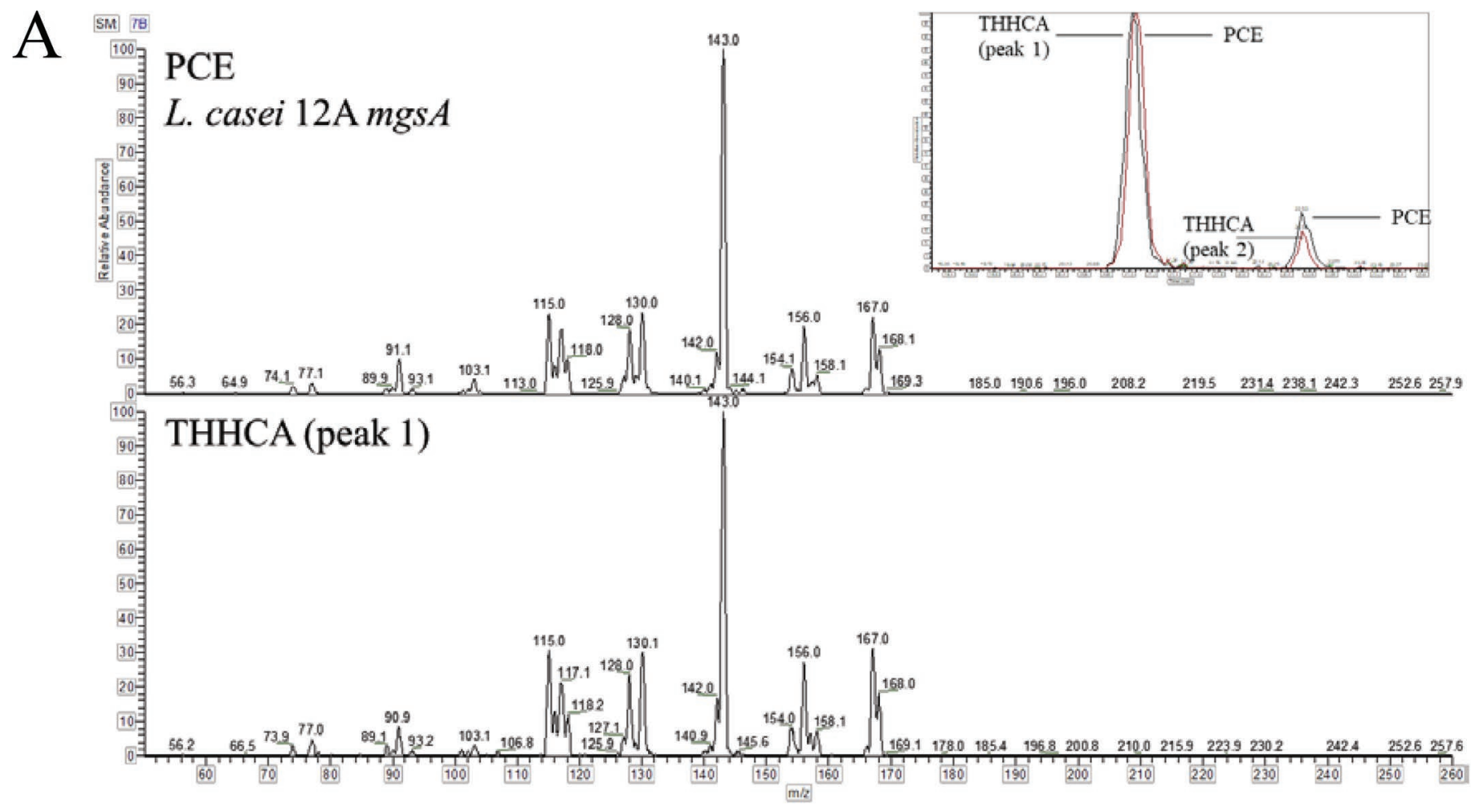

$\mathrm{B}$

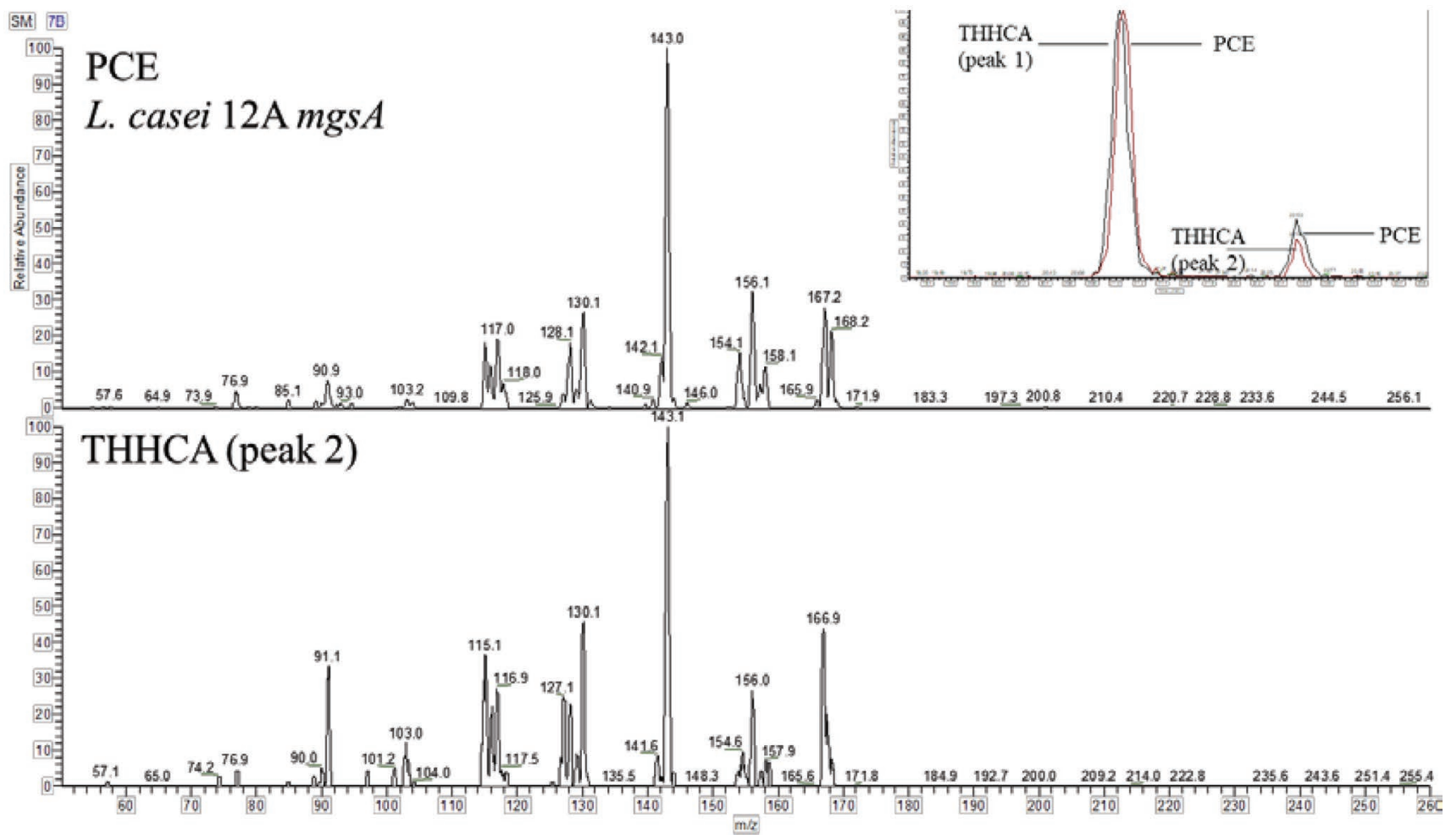

Figure 4. Liquid chromatography tandem mass spectrometry (LC-MS/MS) comparison between $\beta$-carboline derivatives formed in Parmesan cheese extract (PCE) from Lactobacillus casei 12A expressing methylglyoxal synthase $(m g s A)$ and 1,2,3,4-tetrahydroharmane-3-carboxylic acid (THHCA; A) peak 1 and (B) peak 2. The mass to charge ratio $(\mathrm{m} / z)$ of fragment ions and their relative abundance in samples and commercially available standards were generated using a collision energy of $40 \mathrm{eV}$ and detected by LC-MS/MS (Thermo TSQ Quantum Discovery Max, Thermo Fisher Scientific, Waltham, MA). The co-elution profile of the sample and the standard is depicted in the upper right-hand corner of each mass spectrum. 

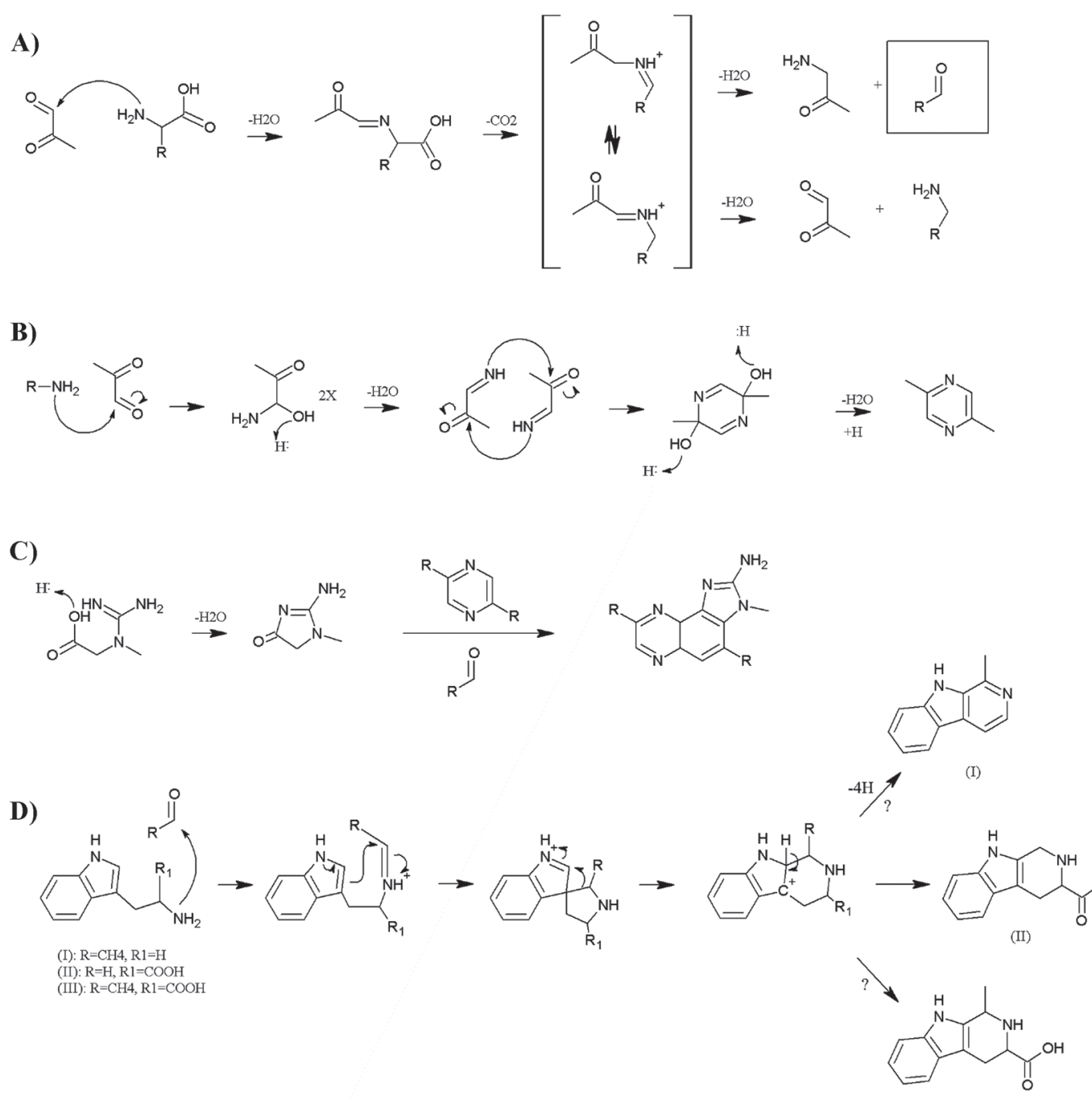

(III)

Figure 5. Possible methylglyoxal (MG)-contributing reaction mechanisms for the formation of heterocyclic amines. (A) Formation of aldehydes (box) from Strecker degradation of MG and AA (Nursten, 2005). (B) Formation of 2,5-dimethyl-pyrazine from condensation of MG (Rizzi, 2008). (C) Formation of imidazo-quinoxaline derivatives from the condensation of creatine to creatinine and subsequent reaction with pyrazine and aldehyde constituents (Jägerstad and Skog, 1991; Skog et al., 1992). (D) Formation of (I) Harman, (II) 1,2,3,4-tetrahydro- 3 -carboline-3carboxylic acid, and (III) 1,2,3,4-tetrahydroharmane-3-carboxylic acid from the Pictet-Spengler condensation of formaldehyde (R = H) or acetaldehyde $\left(\mathrm{R}=\mathrm{CH}_{4}\right)$ with tryptamine $\left(\mathrm{R}_{1}=\mathrm{H}\right)$ or tryptophan $\left(\mathrm{R}_{1}=\mathrm{COOH}\right.$; Cox and Cook, 1995).

cheese and may exacerbate browning during ripening and cold-storage periods. We demonstrate that the microbial production of $\mathrm{MG}$ leads to browning and heterocyclic amine formation in PCE despite atypical conditions supporting Maillard reactions. Determining the effects of MG synthase activity in Parmesan cheese may help implicate specific MG-producing NSLAB so that industry can focus on mitigating their occurrence.

This study used PCE to simulate constituents of Parmesan that would readily react with MG. Moreover, the plasmid-born overexpression of transgenic $m g s A$ was used as a tool for the in vivo production of MG in L. casei, a method which we find differs from the exogenous addition of MG in respect to the amount of reaction products formed. The presence of $m g s A$ is distributed in at least 17 species of Lactobacillus to date, according to the GenBank database (Benson et al., 2017). To detect the formation of MG adducts from bacterial overexpression of $m g s A$, we required conditions that increased the magnitude of MG production, such as the inclusion of $2 \%$ glucose and growth at $37^{\circ} \mathrm{C}$. Furthermore, because MG is bacteriostatic, we used an inducible system for timely expression of $m g s A$ once a relatively higher cell density was achieved. The $m g s A$ gene from T. thermosaccharolyticum HG-8 has been previously shown to efficiently catalyze the conversion 
of DHAP to MG and its nucleotide sequence was codon optimized for expression in L. casei (Supplemental Figure S1; https://doi.org/10.3168/jds.2018-15042; Altaras et al., 2001). We demonstrate the ability of the system to cause browning in PCE as a result of MG production and determine the formation of heterocyclic amines including $\beta$-carboline derivatives, which pose larger implications toward functional, nutritional, and quality aspects of affected cheeses.

Beta-carbolines are naturally occurring hetero-tricyclic alkaloids that are also readily produced during production, processing, and storage of food. The essential skeleton is composed of a pyridine ring and indole group and is derived from Pictet-Spengler condensation of indolethylamines and aldehydes or $\alpha$-ketoacids (Cox and Cook, 1995; Maryanoff et al., 2004).

Beta-carbolines are considered mutagenic and carcinogenic compounds, and have been extensively studied for their neurochemical and pharmacological action (Airaksinen and Kari, 1981; Wakabayashi et al., 1997; Husbands et al., 2001; Totsuka et al., 2004; Miralles et al., 2005; Herraiz et al., 2010). Beta-carbolines are bioactive compounds, hence dietary exposure and their presence in foodstuffs have garnered much interest. Tetrahydro- $\beta$-carbolines and the fully aromatic oxidized form, Harman, have been extensively determined to occur naturally in many commercial foods such as fruit juices, soft drinks, fermented alcoholic beverages, fermented sauces, vinegar, meats, fish, cheese, yogurt, toasted bread, and coffee (Sen et al., 1995; Herraiz and Sanchez, 1997; Herraiz, 2000a,b,c, 2002; Herraiz and Galisteo, 2002; Pfau and Skog, 2004). High temperature cooking applications associated with Maillard chemistry, such as smoking, grilling, and frying of foods, have been shown to augment the formation of $\beta$-carbolines (Herraiz and Papavergou, 2004; Louis et al., 2007; Kim and Lee, 2010; Dong et al., 2011). Smoked foods accumulate greater amounts of $\beta$-carbolines, presumably caused by a reaction between the formaldehyde present in smoke and tryptophan (Papavergou and Herraiz, 2003). Our study suggests that MG readily contributes toward the formation of heterocyclic amines such as $\beta$-carbolines in Parmesan cheese, despite the relative absence of high temperatures commonly associated with Maillard browning.

Free AA and small peptides are abundantly available as potential reactants in water-soluble Parmesan cheese extracts similar to the one used in our study (Hillmann and Hofmann, 2016). Strecker degradation of $\alpha$-AA into aldehydes occurs during intermediate stages of the Maillard reaction and is accelerated by the presence of $\alpha$-dicarbonyl compounds such as MG (Nursten, 2005). In this respect, formaldehyde and acetaldehyde can form from $\alpha$-dicarbonyl-assisted oxidative decar- boxylation of glycine and alanine, respectively. Therefore, aldehyde-amine condensation of acetaldehyde and tryptamine presents one possible explanation for the observed formation of the Harman-like compound in our study. Similarly, condensation of formaldehyde or acetaldehyde with tryptophan can derive TH $\beta \mathrm{CA}$ and 1-methyl-3,4-dihydro- $2 \mathrm{H}$ - $\beta$-carboline-3-carboxylic acid, respectively.

This mechanism is evidenced by a study by Masuda et al. (2005), which incubated the Maillard reaction products MG, glyoxal, 3-deoxy-D-glucosonone, or furfural with tryptophan in buffered solution at $37^{\circ} \mathrm{C}$ for $4 \mathrm{wk}$ and detected the formation of several $\beta$-carboline derivatives. Similarly, Nemet and Verga-Defterdarović (2008) demonstrated the formation of 1-acetyl- $\beta$ carboline from the reaction of MG with tryptophan, its methyl ester, or tryptamine. Together, these findings corroborate that MG can lead to the formation of $\beta$-carbolines by nonenzymatic conversion of indole compounds. Indeed, we analyzed PCE containing the exogenous addition of commercially available MG and found the formation of a single differential compound from the control. Both the biological production of $\mathrm{MG}$ and its exogenous addition to PCE leads to the formation of TH $\beta \mathrm{CA}$; however, the exogenous addition of MG does not account for all the compounds detected herein. After exogenously adding MG to PCE we did not detect the formation of compounds that would otherwise resemble the ones found from expressing mgs $A$ in L. casei. This discrepancy between exogenously added and bacterially produced MG could be explained by the different abundances of hydrated MG species in solution, reflecting a variation in preferential reactions. Methylglyoxal persists as a mono- or dihydrate through proton addition of either carbonyl group in aqueous solution. Both aldehylic and ketonic carbonyl groups form a geminal diol, in which the former group is thermodynamically more favorably hydrated (Nemet et al., 2004; Krizner et al., 2009; Axson et al., 2010). In neutral $\mathrm{pH}$ solution, the distribution of monohydrate, dihydrate, and unhydrated species is reported to be $56 \%, 44 \%$, and trace amounts, respectively (McLellan and Thornalley, 1992).

Aldehyde-amine condensations are known to give rise to polymeric, high molecular mass, colored products consisting of heterocyclic ring systems. The observed compounds with chemical compositions of $\mathrm{C}_{13} \mathrm{H}_{8} \mathrm{~N}_{4} \mathrm{O}_{4}$, $\mathrm{C}_{17} \mathrm{H}_{18} \mathrm{~N}_{2} \mathrm{O}_{5}, \quad \mathrm{C}_{9} \mathrm{H}_{10} \mathrm{~N}_{4} \mathrm{O}_{3} \mathrm{~S}$, and $\mathrm{C}_{8} \mathrm{H}_{10} \mathrm{~N}_{4} \mathrm{OS}$ are likely also nitrogenous heterocycles, as inferred from their carbon to hydrogen ratio; however, further analysis is required for structural determination of pyrazine, pyridine, pyrole, and imidazole sub-groups. Aldehydes can also react with each other by aldol condensation to derive cyclic compounds that are nitrogen-free, such as 
the observed pyrone or quinone with chemical composition $\mathrm{C}_{6} \mathrm{H}_{6} \mathrm{O}_{3}$.

\section{CONCLUSIONS}

We demonstrate that overexpressing MG synthase in L. casei readily contributes toward browning of a Parmesan cheese extract and leads to the formation of heterocyclic amines, including some $\beta$-carbolines. These findings pose greater significance on the quality of fermented foods because MG is a microbial metabolite able to accelerate the formation of Maillard reaction products in the absence of high temperatures and reducing sugars. Moreover, affected cheeses exhibiting similar reaction products to the ones determined herein merit closer examination for atypical microbiota that might contribute MG synthase activity. The use of $m g s A$ as a genetic biomarker for the detection and control of offending microbiota could prove useful for improving the quality control of affected cheeses. Culture-independent methods for the detection of the gene mgs $A$ in cheese might serve as an indication of MG-based browning in this manner. However, further studies are required to determine the frequency of association between $\mathrm{mgsA}$ containing microbiota and affected cheeses as well as the extent contributed toward MG-mediated browning.

\section{ACKNOWLEDGMENTS}

We thank the Wisconsin Alumni Research Foundation (Madison) for their support. This study made use of the Mass Spectrometry Facility in the Biotechnology Center at the University of Wisconsin (Madison).

\section{REFERENCES}

Airaksinen, M. M., and I. Kari. 1981. $\beta$-Carbolines, psychoactive compounds in the mammalian body. Part II: Effects. Med. Biol. 59:190-211.

Altaras, N. E., M. R. Etzel, and D. C. Cameron. 2001. Conversion of sugars to 1,2-propanediol by Thermoanaerobacterium thermosaccharolyticum HG-8. Biotechnol. Prog. 17:52-56.

Axson, J. L., K. Takahashi, D. O. De Haan, and V. Vaida. 2010. Gasphase water-mediated equilibrium between methylglyoxal and its geminal diol. Proc. Natl. Acad. Sci. USA 107:6687-6692.

Benson, D. A., M. Cavanaugh, K. Clark, I. Karsch-Mizrachi, D. J. Lipman, J. Ostell, and E. W. Sayers. 2017. GenBank. Nucleic Acids Res. 45:D37-D42.

Booth, I. R., G. P. Ferguson, S. Miller, C. Li, B. Gunasekera, and S. Kinghorn. 2003. Bacterial production of methylglyoxal: A survival strategy or death by misadventure? Biochem. Soc. Trans. 31:1406-1408.

Broadbent, J. R., M. F. Budinich, and J. L. Steele. 2011. Cheese: NSLAB. Pages 639-644 in Encyclopedia of Dairy Science. 2nd ed. J. Fuquay, P. Fox, and P. McSweeney, ed. Academic Press, Burlington, MA.

Chaplen, F. W., W. E. Fahl, and D. C. Cameron. 1996. Method for determination of free intracellular and extracellular methylglyoxal in animal cells grown in culture. Anal. Biochem. 238:171-178.
Compendium of International Analysis of Methods. 2010. Methods for the Determination of Alpha-Dicarbonyl Compounds of Wine by GC After Derivitization by 1,2-Diaminobenzene. International Organisation of Vine and Wine. OIV-MA-AS315-21.

Cooper, R. A. 1984. Metabolism of methylglyoxal in microorganisms. Annu. Rev. Microbiol. 38:49-68.

Cox, E., and J. Cook. 1995. The Pictet-Spengler condensation: A new direction for an old reaction. Chem. Rev. 95:1797-1842.

Divine, R. D., and S. A. Rankin. 2013. Short communication: Reducing agents attenuate methylglyoxal-based browning in Parmesan cheese. J. Dairy Sci. 96:6242-6247.

Divine, R. D., D. Sommer, A. Lopez-Hernandez, and S. A. Rankin. 2012. Short communication: Evidence for methylglyoxal-mediated browning of Parmesan cheese during low temperature storage. J. Dairy Sci. 95:2347-2354.

Dong, A., J. Lee, and H.-S. Shin. 2011. Formation of amino-imidazoazaarenes and carbolines in fried beef patties and chicken breasts under different cooking conditions in Korea. Food Sci. Biotechnol. 20:735-741.

Falahati, H., M. Pazhang, S. Zareian, N. Ghaemi, R. Rofougaran, A. Hofer, A. R. Rezaie, and K. Khajeh. 2013. Transmitting the allosteric signal in methylglyoxal synthase. Protein Eng. Des. Sel. $26: 445-452$

Ferguson, G. P., S. Tötemeyer, M. J. MacLean, and I. R. Booth. 1998. Methylglyoxal production in bacteria: Suicide or survival? Arch. Microbiol. 170:209-218.

Fitzsimons, N. A., T. M. Cogan, S. Condon, and T. Beresford. 2001. Spatial and temporal distribution of non-starter lactic acid bacteria in Cheddar cheese. J. Appl. Microbiol. 90:600-608.

Gibson, D. G., L. Young, R. Y. Chuang, J. C. Venter, C. A. Hutchison, and H. O. Smith. 2009. Enzymatic assembly of DNA molecules up to several hundred kilobases. Nat. Methods 6:343-345.

Grote, A., K. Hiller, M. Scheer, R. Münch, B. Nörtemann, D. C. Hempel, and D. Jahn. 2005. JCat: A novel tool to adapt codon usage of a target gene to its potential expression host. Nucleic Acids Res 33(Web Server issue):W526-531.

Herraiz, T. 2000a. Analysis of tetrahydro-beta-carboline-3-carboxylic acids in foods by solid-phase extraction and reversed-phase highperformance liquid chromatography combined with fluorescence detection. J. Chromatogr. A 871:23-30.

Herraiz, T. 2000b. Tetrahydro-beta-carboline-3-carboxylic acid compounds in fish and meat: Possible precursors of co-mutagenic betacarbolines norharman and harman in cooked foods. Food Addit. Contam. 17:859-866.

Herraiz, T. 2000c. Tetrahydro-beta-carbolines, potential neuroactive alkaloids, in chocolate and cocoa. J. Agric. Food Chem. 48:4900 4904.

Herraiz, T. 2002. Identification and occurrence of the bioactive betacarbolines norharman and harman in coffee brews. Food Addit. Contam. 19:748-754.

Herraiz, T., and J. Galisteo. 2002. Identification and occurrence of the novel alkaloid pentahydroxypentyl-tetrahydro-beta-carboline3-carboxylic acid as a tryptophan glycoconjugate in fruit juices and jams. J. Agric. Food Chem. 50:4690-4695.

Herraiz, T., D. González, C. Ancín-Azpilicueta, V. J. Arán, and H. Guillén. 2010. Beta-Carboline alkaloids in Peganum harmala and inhibition of human monoamine oxidase (MAO). Food Chem. Toxicol. 48:839-845.

Herraiz, T., and E. Papavergou. 2004. Identification and occurrence of tryptamine- and tryptophan-derived tetrahydro-beta-carbolines in commercial sausages. J. Agric. Food Chem. 52:2652-2658.

Herraiz, T., and F. Sanchez. 1997. Presence of tetrahydro-beta-carboline-3-carboxylic acids in foods by gas chromatography-mass spectrometry as their N-methoxycarbonyl methyl ester derivatives. J. Chromatogr. A 765:265-277.

Hillmann, H., and T. Hofmann. 2016. Quantitation of key tastants and re-engineering the taste of Parmesan cheese. J. Agric. Food Chem. 64:1794-1805.

Hopper, D. J., and R. A. Cooper. 1972. The purification and properties of Escherichia coli methylglyoxal synthase. Biochem. J. 128:321-329. 
Husbands, S. M., R. A. Glennon, S. Gorgerat, R. Gough, R. Tyacke, J. Crosby, D. J. Nutt, J. W. Lewis, and A. L. Hudson. 2001. Betacarboline binding to imidazoline receptors. Drug Alcohol Depend. 64:203-208.

Jägerstad, M., and K. Skog. 1991. Formation of meat mutagens. Adv. Exp. Med. Biol. 289:83-105.

Kim, S., and K. G. Lee. 2010. Effects of cooking variables on formation of heterocyclic amines (HCA) in roasted pork and mackerel. J. Toxicol. Environ. Health A 73:1599-1609.

Krizner, H. E., D. O. De Haan, and J. Kua. 2009. Thermodynamics and kinetics of methylglyoxal dimer formation: A computational study. J. Phys. Chem. A 113:6994-7001.

Louis, E. D., W. Zheng, W. Jiang, K. T. Bogen, and G. A. Keating. 2007. Quantification of the neurotoxic beta-carboline harmane in barbecued/grilled meat samples and correlation with level of doneness. J. Toxicol. Environ. Health A 70:1014-1019.

Maryanoff, B. E., H. C. Zhang, J. H. Cohen, I. J. Turchi, and C. A. Maryanoff. 2004. Cyclizations of $\mathrm{N}$-acyliminium ions. Chem. Rev. 104:1431-1628.

Masuda, S., H. Kanamori, and N. Kinae. 2005. Isolation of mutagenic beta-carboline derivatives after nitrite treatment of maillard reaction mixtures and analysis of these compounds from foodstuffs and human urine. Biosci. Biotechnol. Biochem. 69:2232-2235.

McDonald, S. 1992. Role of a-dicarbonyl compounds produced by lactic acid bacteria on the flavor and color of cheeses. $\mathrm{PhD}$ Thesis. Department of Food Science, University of Wisconsin, Madison.

McLellan, A. C., and P. J. Thornalley. 1992. Synthesis and chromatography of 1, 2-diamino-4, 5-dimethoxybenzene, 6, 7-dimethoxy2-methylquinoxaline and 6, 7-dimethoxy-2,3-dimethylquinoxaline for use in a liquid chromatographic fluorimetric assay of methylglyoxal. Analytica Chimic Acta 263:137-142.

Miralles, A., S. Esteban, A. Sastre-Coll, D. Moranta, V. J. Asensio, and J. A. García-Sevilla. 2005. High-affinity binding of beta-carbolines to imidazoline I2B receptors and MAO-A in rat tissues: norharman blocks the effect of morphine withdrawal on DOPA/ noradrenaline synthesis in the brain. Eur. J. Pharmacol. 518:234242.

Nemet, I., and L. Varga-Defterdarović. 2008. The role of methylglyoxal in the non-enzymatic conversion of tryptophan, its methyl ester and tryptamine to 1-acetyl-beta-carbolines. Bioorg. Med. Chem. 16:4551-4562.

Nemet, I., D. Vikić-Topić, and L. Varga-Defterdarović. 2004. Spectroscopic studies of methylglyoxal in water and dimethylsulfoxide. Bioorg. Chem. 32:560-570.
Nursten, H. 2005. The Maillard Reaction: Chemistry, Biochemistry, and Implications. The Royal Society of Chemistry, Cambridge, UK.

Papavergou, E., and T. Herraiz. 2003. Identification and occurrence of 1,2,3,4-tetrahydro-B-carboline-3-carboxylic acid: the main Bcarboline alkaloid in smoked foods. Food Res. Int. 36:843-848.

Pfau, W., and K. Skog. 2004. Exposure to beta-carbolines norharman and harman. J. Chromatogr. B Analyt. Technol. Biomed. Life Sci $802: 115-126$.

Rizzi, G. 2008. The Strecker degradation of amino acids: Newer avenues for flavor formation. Food Rev. Int. 24:416-435.

Saadat, D., and D. H. Harrison. 1999. The crystal structure of methylglyoxal synthase from Escherichia coli. Structure 7:309-317.

Sen, N., S. Seaman, B. P.-Y. Lau, D. Weber, and D. Lewis. 1995. Determination and occurrence of various tetrahydro-b-carboline3 -carboxylic acids and the corresponding $\mathrm{N}$-nitroso compounds in foods and alcoholic beverages. Food Chem. 54:327-337.

Skog, K., M. G. Knize, J. S. Felton, and M. Jägerstad. 1992. Formation of new heterocyclic amine mutagens by heating creatinine, alanine, threonine and glucose. Mutat. Res. 268:191-197.

Solieri, L., A. Bianchi, and P. Giudici. 2012. Inventory of non starter lactic acid bacteria from ripened Parmigiano Reggiano cheese as assessed by a culture dependent multiphasic approach. Syst. Appl. Microbiol. 35:270-277.

Sørvig, E., G. Mathiesen, K. Naterstad, V. G. Eijsink, and L. Axelsson. 2005. High-level, inducible gene expression in Lactobacillus sakei and Lactobacillus plantarum using versatile expression vectors. Microbiology 151:2439-2449.

Totsuka, Y., T. Takamura-Enya, R. Nishigaki, T. Sugimura, and K. Wakabayashi. 2004. Mutagens formed from beta-carbolines with aromatic amines. J. Chromatogr. B Analyt. Technol. Biomed. Life Sci. 802:135-141.

Wakabayashi, K., Y. Totsuka, K. Fukutome, A. Oguri, H. Ushiyama, and T. Sugimura. 1997. Human exposure to mutagenic/carcinogenic heterocyclic amines and comutagenic beta-carbolines. Mutat. Res. 376:253-259.

Weber, J., A. Kayser, and U. Rinas. 2005. Metabolic flux analysis of Escherichia coli in glucose-limited continuous culture. II. Dynamic response to famine and feast, activation of the methylglyoxal pathway and oscillatory behaviour. Microbiology 151:707-716.

Welker, D. L., J. E. Hughes, J. L. Steele, and J. R. Broadbent. 2015 High efficiency electrotransformation of Lactobacillus casei. FEMS Microbiol. Lett. 362:1-6. 